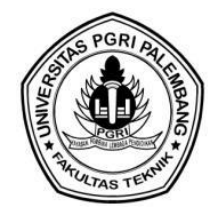

\title{
OPTIMALISASI WILAYAH PENGALIRAN BOOSTER KENTEN DENGAN PERHITUNGAN HEADLOSS
}

\author{
Reni Andayani*, Lega Reskita Lubis \\ Prodi Teknik Sipil, Teknik, Universitas Tridinanti \\ *Corresponding Author, email: reni_andayani@univ-tridinanti.ac.id
}

\begin{abstract}
ABSTRAK
Kebutuhan sehari-hari air bersih sebagai air minum bagi makhluk hidup sangatlah penting, dan perlu suatu analisis jaringan perpipaan untuk mencukupinya. Analisis jaringan perpipaan sangat komplek dan perhitungannya harus akurat. Sistem jaringan distribusi untuk air minum tentunya penggunaan pipa adalah yang utama, dimana perlu diperhatikan faktor kehilangan tinggi tekanan (headloss). Dan perlu diperhatikan debit dan tekanan yang terjadi, karena semakin besar debit dan kehilangan tinggi tekanan pipa, maka akan berdampak pada distribusi air yang tidak lancar. Kehilangan suatu energi adalah faktor yang berpengaruh terhadap kapasitas pipa sebagai sarana distribusi air, karena debit aliran air akan berkurang. Kehilangan energi disebabkan oleh koefisien gesek pada pipa, perubahan penampang penampang yang ada pada pipa, dan belokan pipa di sepanjang pipa yang digunakan dan panjang pipa juga dapat mempengaruhi kehilangan energi pada pipa. Pada tahun 2019 untuk wilayah pengaliran Booster Kenten pada jaringan pipa distribusi air bersihnya mengalami kehilangan tinggi tekan (hgs), dan yang terbesar pada pipa blok 5 yaitu 1,82 atm, sementara pipa blok 12 yang terkecil yaitu 0,01 atm dengan kehilangan tinggi tekan ratarata $0,33 \mathrm{~atm}$
\end{abstract}

Kata Kunci : Jaringan Distribusi, Kehilangan Tinggi Tekanan, Booster Kenten

\begin{abstract}
The daily need for clean water as drinking water for living things is very important, and an analysis of the pipeline network is needed to fulfill it. Analysis of the piping network is very complex and the calculations must be accurate. The distribution network system for drinking water, of course, the use of pipes is the main one, which needs to be considered the factor of high pressure loss (headloss). And it is necessary to pay attention to the discharge and pressure that occurs, because the greater the discharge and the high loss of pipe pressure, it will have an impact on the distribution of water that is not smooth. The loss of an energy is a factor that affects the pipe capacity as a means of distributing water, because the water flow rate will decrease. Energy losses caused by the friction coefficient in the pipe, changes in the cross-section of the pipe, and pipe bends along the pipe used and the length of the pipe can also affect the energy loss in the pipe. In 2019 the Booster Kenten drainage area in its clean water distribution pipeline experienced a loss of compressive height (hgs), and the largest was in pipe block 5, namely 1.82 atm, while the smallest block 12 pipe was $0.01 \mathrm{~atm}$ with a loss of compressive height. an average of $0.33 \mathrm{~atm}$
\end{abstract}

Keywords : Distribution Network, Headloss, Booster Kenten

\section{PENDAHULUAN}

Pertumbuhan penduduk Kota Palembang yang tinggi mempunyai dampak yang besar pula untuk kebutuhan air. Air yang ada di bumi mengalami siklus yang disebut daur hydrologi (Asdak, 2010), dan kuantitas air yang didapat bumi bersifat tetap, tetapi kualitas airnya terutama untuka air minum harus diolah atau di proses terlebih dahulu secara bertahap. Air minum merupakan air bersih yang sudah melalui proses pengolahan dan memenuhi syarat kesehatan (Permenkes RI No. 492 tahun 2010). Wilayah Kota Palembang sebagian besar mengunakan layanan PDAM Tirta Musi sebagai penyalur air bersihnya. Perusahaan Daerah Air Minum (PDAM) Tirta Musi memiliki 7 booster pengolahan air brsih dan melayani 295.177 pelanggan $(88,75 \%$ jumlah penduduk kota 
Palembang). Fungsi pokok jaringan pipa distribusi adalah sebagai media penghantar air bersih ke pelanggan dengan selalup memperhatikan faktor kualitas, kuantitas dan tekanan air (Putri, 2018). Booster berfungsi sebagai sarana pemenuhan distribusi air pada lokasi dengan jarak atau ketinggian tertentu yang sulit dijangkau secara maksimal bila digunakan pompa air terutama pompa air spesifikasi daya dorong rendah. Untuk menjangkau area pelayanan dan tingkat pelayan yang maksimal, maka pendistribusian air harus memperhatikan tekanan air sisa paling rendah $5 \mathrm{mka}(0,5 \mathrm{~atm})$ dan tekanan paling tinggi 22 mka yang setara gedung 6 lantai (Kepmendagri No.47 Tahun 1999).

Kehilangan tinggi tekanan (headloss) pada jaringan pipa dipengaruhi oleh beberapa faktor yang harus diperhatikan. Kehilangan tinggi tekanan dibedakan menjadi 2 jenis, yaitu kehilangan tinggi tekanan utama/primer (major losses) dan kehilangan tinggi tekanan sekunder (minor losses), di mana major losses terjadi dikarenkan adanya gesekan air dan permukaan pipa bagian dalam, sedangkan minor losses terjadi dikarenakan air yang mengalir pada pipa yang disambung dengan sudut belokan, perubahan penampang (dari kecil ke besar ataupun dari besar ke kecil), dan pipa yang dibuat bercabang. Dalam perencanaan distribusi air bersih, sistem jaringan perpipaan adalah sistem yang paling mahal, sehingga perhitungan sistem distribusinya harus teliti agar pendistribusiannyan efisien. Agar sistem jaringan pipanya terutama pipa jaringan tertutup dapat diseragamkan maka dapat digunakan metode Hardy-Cross, karena pada metode Hardy-Cross, pipa yang akan dianalisa harus berupa sistem jaringan tertutup (loop) dengan asumsi setiap aliran pada semua ruas dianggap seragam (uniform) (Kodoatie, 2002). Kehilangan tinggi tekanan ini terjadi pada wilayah pengaliran booster kenten PDAM Tirta Musi palembang. Kondisi jaringan pipa pada wilayah pengaliran booster kenten memiliki tekanan mencapai 4,7 atm. Namun setelah air didistribusikan tekanan aliran air menjadi kecil sehingga kuantitas air tidak memenuhi kebutuhan pelanggan. Oleh karenanya, perlu dilakukan kajian perhitungan tekanan di wilayah pengaliran Booster Kenten guna pelayanan air bersih dari PDAM Tirta Musi secara optimal.

\section{METODE PENELITIAN}

Penelitian dilaksanakan di wilayah distribusi booster Kenten, yaitu dari Jalan MP. Mangkunegara sampai dengan Jalan Serasan dengan luas wilayah $\pm 1,12 \mathrm{~km}^{2}$. Data yang dikumpulkan yaitu : data primer berupa tekanan air dalam pipa, yang diambil dari beberapa titik pantau, baik di lokasi kontur tertinggi maupun di ujung pengaliran, yang nantinya menjadi panduan untuk menghitung semua tekanan jaringan pipa di wilayah pendistribusian Booster Kenten, di mana perhitungan tekanannya dilihat dari manometer permanen dan manometer portable yang dipasang pada kran-kran air di titik pantau tekanan, dan kemudian data diambil setiap 1 jam selama pendistribusian dari booster Kenten. Data sekunder berupa informasi instansi setempat dan melalui penelusuran jaringan internet seperti : (1) data jumlah pelanggan tahun 2019 di wilayah pendistribusian booster Kenten (data dari PDAM Tirta Musi Palembang), (2) data suplai air kepelanggan perharinya, (3) peta jaringan area pendistribusian booster Kenten (dari PDAM TirtaMusi Palembang), berupa data booster, volume reservoir, diameter pipa, dan panjang pipa yang terpasang, (4) peta Topografi (dari Bappeda Kota Palembang). 


\section{HASIL DAN PEMBAHASAN}

Luas wilayah studi adalah sebesar $1.120 .000 \mathrm{~m}^{2}$, memiliki kontur tertinggi sebesar 17 mdpl di Jalan Rahmat dan kontur terendah sebesar 2 mdpl di jalan Serasan. Panjang pipa distribusi yang berada dilokasi yaitu $23.162 \mathrm{~m}$ '.

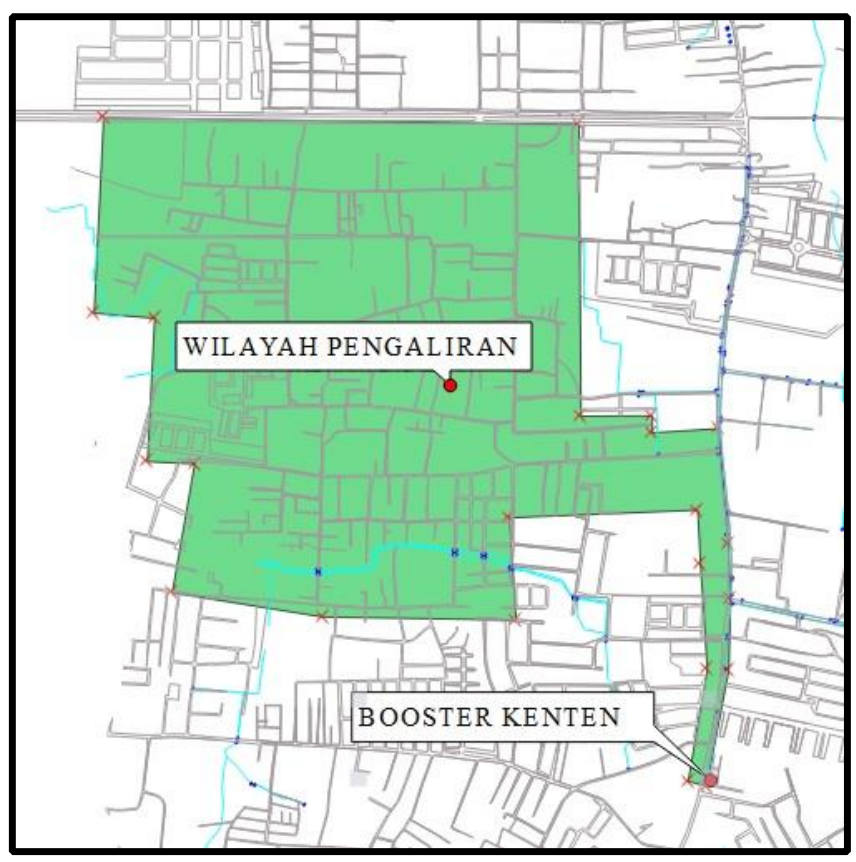

Gambar 1. Peta Wilayah Pengaliran Booster Kenten

Di wilayah distribusi booster Kenten belum memiliki jadwal pengaliran selama 24 jam dan di wilayah tersebut terdata 1.622 pelanggan, yang di dominasi bangunan rumah tangga kelas menengah ke bawah serta beberapa bangunan ruko.

Pengumpulan data sekunder didapat langsung dari PDAM Tirta Musi Palembang, yang berupa jumlah pelangggan, klasifikasi pelanggan, data didistribusi air yang dialirkan ke pelanggan, dan peta jaringan pipa distribusi pelanggan. Berdasarkan Kriteria Perencanaan Dirjen Cipta Karya Dinas PU (1996), untuk katagori kota besar, pemakaian air dengan kriteria rumah tangga sebesar 150 liter/orang/hari atau 0,05 liter/detik per unit rumah tangga. Atau sambungan layanan perpipaan untuk rumah tangga berkriteria jumlah anggota keluarga 5 orang (Ferdiansyah, 2017). Untuk analisis sektor non domestik berpatokan pada analisis data pertumbuhan terakhir fasilitas sosial ekonomi yang ada di wilayah perencanaan (Andayani \& Nurmansyah, 2017). Perhitungan total pemakaian air pelanggan yang dapat dilihat pada tabel berikut :

Tabel 1. Golongan Pelanggan Wilayah Distribusi Booster Sako Kenten

\begin{tabular}{|c|l|c|c|c|}
\hline No & \multicolumn{1}{|c|}{ Klasifikasi Pelanggan } & $\begin{array}{c}\text { Jumlah } \\
\text { Pelanggan } \\
2019 \text { (SL) }\end{array}$ & $\begin{array}{c}\text { Pemakaian } \\
\text { Air PerUnit } \\
\text { (L/det) }\end{array}$ & $\begin{array}{c}\text { Total Pemakaian } \\
\text { Pelanggan L/det) }\end{array}$ \\
\hline 1 & Rumah Tinggal & 1568 & 0,05 & 73,5 \\
\hline 2 & Tempat Ibadah (Masjid) & 17 & 0,19 & 3,3 \\
\hline 3 & Pertokoan / Tempat Usaha (Ruko) & 28 & 0,12 & 3,4 \\
\hline 4 & Sekolah (SD) & 3 & 0,47 & 1,4 \\
\hline 5 & Gudang Total & 6 & 0,48 & 2,9 \\
\hline \multicolumn{2}{|c|}{} & 1622 & 1,31 & 84,5 \\
\hline
\end{tabular}


Berdasarkan tabel 1 di atas, data yang didapat dari PDAM Tirta Musi Palembang, menyatakan bahwa jumlah pemakaian air tertinggi terdapat pada sambungan rumah tangga yaitu sebesar 73,5 L/Det, dengan total pemakaian pelanggan di wilayah distribusi booster Kenten pada tahun 2019 sebesar 84,5 L/Det.

Peta jaringan pipa distribusi PDAM Tirta Musi wilayah distribusi booster Kenten terdiri dari jenis pipa PVC, HDPE, AC dan ukuran pipa yang dapat dilihat pada table berikut :

Tabel 2. Data Jaringan Pipa Wilayah Distribusi Booster Kenten

\begin{tabular}{|c|c|c|c|}
\hline No & $\begin{array}{c}\text { Diameter Pipa } \\
(\mathrm{mm})\end{array}$ & $\begin{array}{c}\text { Jenis } \\
\text { Pipa }\end{array}$ & $\begin{array}{c}\text { Panjang } \\
\text { Pipa (m) }\end{array}$ \\
\hline 1 & 63 & PVC & 8.633 \\
\hline 2 & 63 & HDPE & 340 \\
\hline 3 & 90 & PVC & 5.643 \\
\hline 4 & 110 & PVC & 3.986 \\
\hline 5 & 160 & PVC & 3.138 \\
\hline 6 & 200 & HDPE & 95 \\
\hline 7 & 300 & PVC & 346 \\
\hline 8 & 300 & HDPE & 376 \\
\hline 9 & 400 & AC & 605 \\
\hline \multicolumn{4}{|c}{ Total } \\
\hline
\end{tabular}

Dari tabel 2 di atas diketahui bahwa total panjang pipa di wilayah distribusin booster Kenten adalah $23.162 \mathrm{~m}$. Pipa yang paling banyak dipasang adalah pipa berdiameter $63 \mathrm{~mm}$. Rata-rata pipa yang terpasang di wilayah distribusin booster Kenten merupakan material PVC, dengan berbagai diameter pipa, jenis pipa dan panjang pipa eperti ditampilkani pada tabel 2 di atas. Peta jaringan pipa distribusi distribusi booster Kenten dapat dilihat pada gambar berikut :
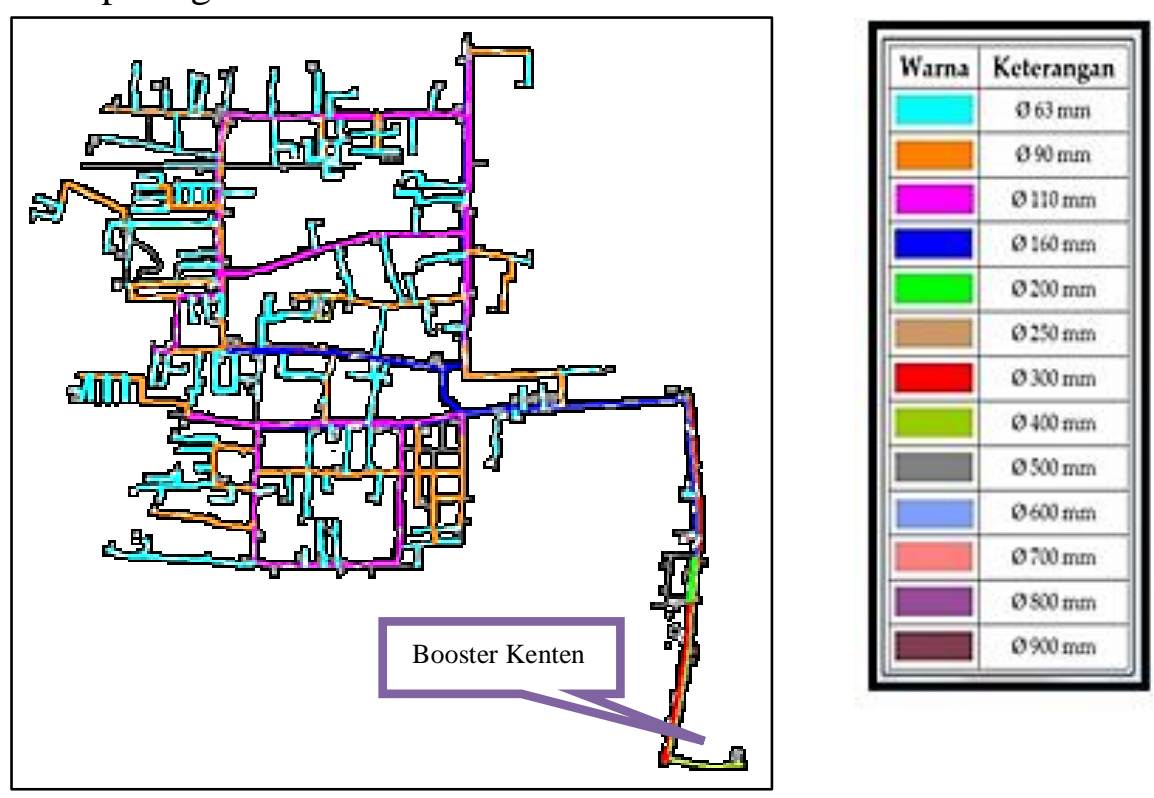

Gambar 2. Peta Jaringan Pipa Distribusi Pengaliran Booster Kenten 
Metode Hardy Cross digunakan untuk menghitung kehilangan tinggi tekan di pipa atau sisa tekanan pada pipa, tetapi tidak untuk menghitung tekanan di junction atau ujung pipa. Dikarenakan jumlah pipa yang banyak yaitu berjumlah 314 pipa, maka perhitungan dilakukan dengan cara dibagi menjadi 14 blok besar yang tiap blok bersumber pada pipa induk utama (Ø 110 - 400 mm). Untuk menghitung kehilangan tinggi tekanan (hgs), maka diperlukan data panjang pipa (L) terpasang, diameter pipa (Ø) terpasang, debit awal (Q) distribusi air. Dimana $\mathrm{Q}$ yang digunakan adalah $\mathrm{Q}_{\text {layanan. }} \mathrm{Q}_{\mathrm{Awal}}$ adalah debit ketersedian air pada tiap blok dan $\mathrm{Q}_{\text {Losses }}$ adalah kehilangan air akibat kebocoran pipa dan sambungan pipa. Karena Booster Kenten merupakan bagian dari unit pelayanan Sako Kenten, maka data kehilangan air didapat dari unit tersebut, dimana jumlah distribusi air yang ada $10.029 .567 \mathrm{~m}^{3}$, dan air yang menjadi rekening sebesar $8.370 .658 \mathrm{~m}^{3}$, maka air yang tidak berekening sebesar 1.658.909 $\mathrm{m}^{3}$ (16,54\%). Sehingga di wilayah distribusi booster Kenten terjadi kehilangan air $\left(\mathrm{Q}_{\text {Losses }}\right)$ sebesar $16,54 \%$ dari $\mathrm{Q}_{\text {awal }}(2,47 \mathrm{~L} / \mathrm{det})$..

Perhitungan debit awal tiap blok di wilayah distribusi booster Kenten dapat dilihat pada tabel berikut :

Tabel 3. Perhitungan Debit Awal Tiap Blok Wilayah Distribusi Booster Kenten

\begin{tabular}{|c|c|c|c|c|c|}
\hline Blok & $\begin{array}{l}\text { Diameter } \\
\text { Pipa } \\
\text { Sumber } \\
(\mathrm{mm}) \\
\end{array}$ & Sambungan Layanan & $\begin{array}{c}\mathrm{Q} \\
\text { Awal } \\
\text { (L/Det) } \\
\text { (a) }\end{array}$ & $\begin{array}{l}\text { Q Losses } \\
16,54 \% \\
\text { (L/Det) } \\
\text { (b) }\end{array}$ & $\begin{array}{l}\text { Q Layanan } \\
\text { (L/Det) } \\
(\mathrm{a}+\mathrm{b})\end{array}$ \\
\hline 1 & 160 & $\begin{array}{l}281 \text { rumah }+2 \text { tempat } \\
\text { ibadah }+1 \text { gudang }\end{array}$ & 14,91 & 2,47 & 17,38 \\
\hline 2 & 160 & $\begin{array}{l}536 \text { rumah }+5 \text { tempat } \\
\text { ibadah }+7 \text { ruko }+ \text { blok } 1+ \\
\text { blok } 3\end{array}$ & 48,03 & 7,94 & 55,97 \\
\hline 3 & 110 & $\begin{array}{l}59 \text { rumah }+2 \text { ruko }+2 \\
\text { tempat ibadah }+2 \text { gudang }\end{array}$ & 4,53 & 0,75 & 5,28 \\
\hline 4 & 160 & $\begin{array}{l}111 \text { rumah }+1 \mathrm{SD}+1 \\
\text { tempat ibadah }+ \text { blok } 2\end{array}$ & 54,24 & 8,97 & 63,21 \\
\hline 5 & 160 & $\begin{array}{l}63 \text { rumah }+3 \text { ruko }+ \text { blok } \\
4\end{array}$ & 57,75 & 9,55 & 67,30 \\
\hline 6 & 110 & $\begin{array}{l}238 \text { rumah }+2 \text { tempat } \\
\text { ibadah }+5 \text { ruko }+1 \text { SD }\end{array}$ & 13,35 & 2,21 & 15,56 \\
\hline 7 & 160 & $\begin{array}{l}219 \text { rumah }+2 \text { tempat } \\
\text { ibadah }+1 \text { ruko }+1 \mathrm{SD}+ \\
\text { blok } 6\end{array}$ & 25,92 & 4,18 & 30,09 \\
\hline 8 & 160 & $\begin{array}{l}65 \text { rumah }+1 \text { tempat } \\
\text { ibadah }+1 \text { ruko }+ \text { blok } 7\end{array}$ & 29,48 & 4,88 & 34,36 \\
\hline 9 & 160 & 18 Rumah + blok 8 & 30,38 & 5,02 & 35,40 \\
\hline 10 & 160 & $\begin{array}{l}\begin{array}{l}3 \text { rumah }+10 \text { ruko }+2 \text { tempat } \\
\text { ibadah }+3 \text { gudang }+ \text { blok } 9\end{array} \\
\end{array}$ & 34,81 & 5,76 & 40,57 \\
\hline 11 & 200 & blok 10 & 34,81 & 5,76 & 40,57 \\
\hline 12 & 300 & blok 11 & 34,81 & 5,76 & 40,57 \\
\hline 13 & 300 & blok 5 & 57,75 & 9,55 & 67,30 \\
\hline 14 & 400 & blok $12+$ blok 13 & 90,65 & 14,99 & 105,64 \\
\hline
\end{tabular}


Perhitungan dilakukan pada tiap blok, hal ini dimaksudkan untuk mempermudah perhitungan tekanan jaringan pipa. Perhitungan debit air dimulai dari pipa induk distribusi terkecil di ujung pengaliran sampai ke pangkal pengaliran pipa induk distribusi utama. Pembagian jaringan distribusi air bersih tiap blok dapat dilihat dari gambar berikut :.

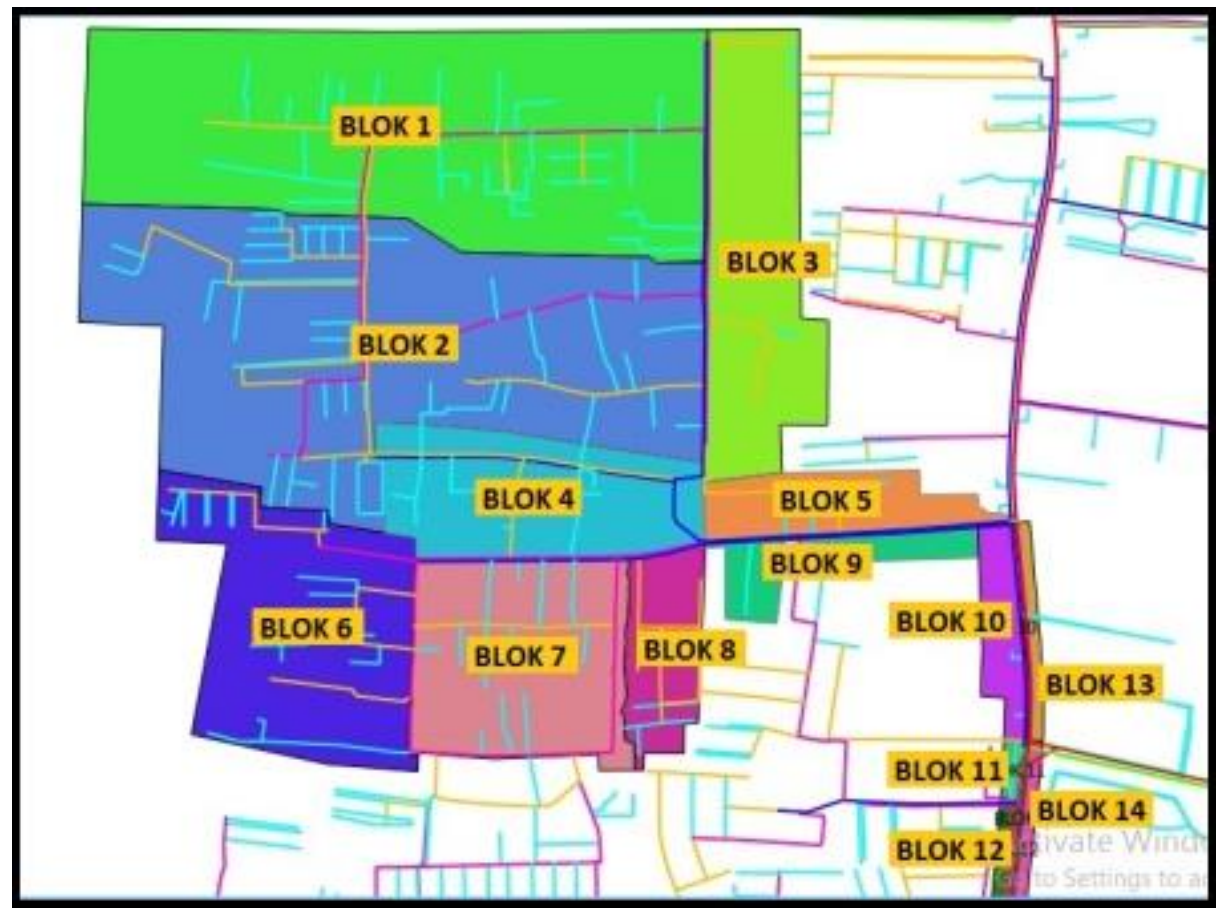

Gambar 3. Pembagian Blok pada pengaliran Booster Kenten

Setelah didapat debit pengaliran pada tiap ruas pipa kemudian langkah berikutnya adalah menghitung kehilangan tinggi tekan (hgs) dengan cara perhitungan Hardy Cross. Dimana perhitungan kehilangan tinggi tekan pada tiap ruas pipa induk distribusi dapat dilihat pada tabel berikut :.

Tabel 4. Perhitungan Kehilangan Tinggi Tekan Pada Tiap Ruas Pipa Induk Distribusi

\begin{tabular}{|c|c|c|c|c|c|c|}
\hline Blok & $\begin{array}{c}\mathrm{D} \\
(\mathrm{m})\end{array}$ & $\begin{array}{c}\mathrm{L} \\
(\mathrm{m})\end{array}$ & Kst & $\begin{array}{c}\text { Q0 } \\
(\mathrm{m} 3 / \mathrm{det})\end{array}$ & $\mathrm{K}$ & $\begin{array}{c}\text { Hgs } \\
(\mathrm{m})\end{array}$ \\
\hline 1 & 0,16 & 399 & 150 & 0,01738 & 3210 & 0,97 \\
\hline 2 & 0,16 & 337 & 150 & 0,05597 & 2711 & 8,49 \\
\hline 3 & 0,11 & 646 & 150 & 0,00528 & 38340 & 1,07 \\
\hline 4 & 0,16 & 116 & 150 & 0,06321 & 933 & 3,73 \\
\hline 5 & 0,16 & 502 & 150 & 0,06730 & 4038 & 18,28 \\
\hline 6 & 0,11 & 451 & 150 & 0,01556 & 26767 & 6,48 \\
\hline 7 & 0,16 & 352 & 150 & 0,03009 & 2831 & 2,56 \\
\hline 8 & 0,16 & 101 & 150 & 0,03436 & 812 & 0,96 \\
\hline 9 & 0,16 & 495 & 150 & 0,0354 & 3983 & 4,99 \\
\hline 10 & 0,16 & 359 & 150 & 0,04057 & 2888 & 4,75 \\
\hline 11 & 0,20 & 93 & 150 & 0,04057 & 228 & 0,38 \\
\hline 12 & 0,30 & 346 & 150 & 0,04057 & 97 & 0,16 \\
\hline 13 & 0,30 & 370 & 150 & 0,06733 & 104 & 0,47 \\
\hline 14 & 0,40 & 441 & 140 & 0,10566 & 31 & 0,35 \\
\hline
\end{tabular}


Sisa tekanan pada ujung pipa dihitung dengan cara mengurangi nilai tekan yang ada, di mana tekanan dari Booster Kenten sebesar 4,7 atm yang dikonversi menjadi 47 meter ( 1 atm = 10 meter). Kehilangan tinggi tekan air dihitung dari tekanan awal di Booster Kenten (A) dan dikurangi kehilangan tinggi tekan pada pipa distribusi. Dan dapat dilihat pada tabel berikut :

Tabel 5. Perhitungan Sisa Tekanan Pada Tiap Ruas Pipa Induk Distribusi

\begin{tabular}{|c|c|c|}
\hline Pipa & $\begin{array}{c}\text { Kehilangan } \\
\text { Tinggi Tekan } \\
\text { Hgs (m) }\end{array}$ & $\begin{array}{c}\text { Sisa } \\
\text { Tekanan (m) }\end{array}$ \\
\hline A & & 47 \\
\hline 14 & 0,35 & 46,65 \\
\hline 13 & 0,47 & 46,18 \\
\hline 5 & 18,28 & 27,90 \\
\hline 4 & 3,73 & 24,17 \\
\hline 3 & 1,07 & 23,10 \\
\hline 2 & 8,49 & 14,61 \\
\hline 1 & 0,97 & 13,64 \\
\hline 12 & 0,16 & 46,49 \\
\hline 11 & 0,38 & 46,11 \\
\hline 10 & 4,75 & 41,36 \\
\hline 9 & 4,99 & 36,37 \\
\hline 8 & 0,96 & 35,41 \\
\hline 7 & 2,56 & 32,85 \\
\hline 6 & 0,35 & 32,50 \\
\hline
\end{tabular}

Dari tabel diatas, tekanan awal yang diberikan PDAM pada Booster Kenten sebesar 4,7 atm, mengalami penurunan karena debit penyadapan yang diperlukan untuk sambungan rumah, tempat ibadah, sekolah, dan ruko. Pipa nomor 1 diatas adalah pipa yang berada di ujung pengaliran, dan sisa tekanan yang didapat hanya sebesar 13,64 m (1,36 atm). Pada pipa 5 terjadi kehilangan tinggi tekan (Hgs) sebesar 18,28 $\mathrm{m}$ dan sisa tekanan adalah sebesar $27,9 \mathrm{~m}$.

\section{KESIMPULAN}

Dari penelitian diatas, maka dapat disimpulkan bahwa setelah diberi tekanan awal pada jaringan distribusi dari booster Kenten sebesar 4,7 atm, terjadi kehilangan tinggi tekan (hgs) pada jaringan pipa distribusi air bersih di wilayah pengaliran booster Kenten tahun 2019, dimana tinggi kehilangan tekanan (hgs) terbesar terjadi di blok 5 sebesar 1,82 atm dengan sisa tekanan 2,79 atm. Dan tinggi kehilangan tekan (hgs) terkecil terjadi di blok 12 yaitu 0,01 atm dengan sisa tekanan 4,65 atm. Sehingga rata-rata kehilangan tinggi tekan (hgs) di wilayah pengaliran booster Kenten tahun 2019 sebesar 0,33 atm

\section{DAFTAR PUSTAKA}

Anonim. Peraturan Menteri Kesehatan RI. No. 492 tahun 2010. Tentang Persyaratan Kualitas Air Minum. 
. Keputusan Mendagri No. 47 Tahun 1999. Pedoman Penilaian Kinerja Perusahaan Daerah Air Minum.

. Kriteria Perencanaan Dirjen Cipta Karya Dinas PU, 1996.

Andayani, R., Djohan, B., \& Nurmansyah, N. (2017). Analisis Kehilangan Tinggi Tekan dan Kebutuhan Air Jaringan Distribusi Air Bersih di Perumnas Talang Kelapa Palembang. Bentang, 5(2), 101-109.

Asdak. C. (2010), Hidrologi dan Pengolaan Daerah Aliran Air Sungai : Edisi Revisi Kelima. Yogyakarta : Gajah Mada Universitas Press Yogyakarta.

Ferdiansyah, H., (2017), Analisa Sistem Distribusi Air Bersih PDAM TirtaMusi Palembang Skripsi, Universitas Tridinanti Palembang.

Kodoatie, R J., (2002). Hidrolika Terapan Aliran Pada Saluran Terbuka dan Pipa. Yoyakarta : Andi.

Putri, Y. E. (2018). Analisa Sistem Distribusi Air Bersih PDAM Tirta Ogan di IKK (Unit) Tanjung Baru. Jurnal Deformasi, 2(2), 48-58. 